\title{
Pulmonary Function Abnormality and Respiratory Tract Irritation Symptoms in Epichlorohydrin-Exposed Workers in Taiwan
}

\author{
Jiin-Chyuan Luo, ${ }^{1,2 *}$ Hsen-Wen Kuo, ${ }^{3}$ Tsun-Jen Cheng, ${ }^{4}$ and Ming J.W. Chang ${ }^{1}$
}

Background Epichlorohydrin (ECH) is a strong irritant of the eyes, respiratory tract, and skin. The aims of this study were to examine the dose-response relationship between observed abnormal pulmonary function tests and respiratory tract irritation symptoms among epichlorohydrin-exposed workers in Taiwan.

Methods A total of 167 workers were randomly selected from a resin synthesis factory. Sixty-six air samples were taken to determine ECH concentration in the workplace. Demographic data, work history, smoking status, and respiratory tract irritation symptoms were gathered by a standard self-administered questionnaire. Pulmonary function tests were also performed.

Results There were 13 of 41 (31.7\%) abnormal mean mid-expiratory flow (MMEF) among the high-ECH-exposed workers, 11 of 38 (29\%) among the low-ECH-exposed workers, and 4 of $59(6.8 \%)$ among non-ECH-exposed workers. There was a significant linear trend between ECH exposure and the prevalence of small airway abnormalities $(P=0.007)$ after adjusting for other factors. There was also a significant dose-response relationship of respiratory tract irritation symptoms (cough, phlegm, chest tightness, and dyspnea) among the ECH-exposed workers.

Conclusions This study suggests that obstructive lung abnormalities and small airway lung damage are associated with ECH exposure. The study also suggests that exposure to very low concentrations $(<0.2 \mathrm{ppm})$ causes significant higher prevalence of respiratory tract irritation symptoms. Causal inferences from the findings cannot be made from this cross-sectional study and further longitudinal studies are needed to better clarify the nature of the observed associations. Am. J. Ind. Med. 43:440-446, 2003. ๑ 2003 Wiley-Liss, Inc.

KEY WORDS: Epichlorohydrin; obstructive lung abnormality; respiratory irritation symptoms

DDepartment of Public Health, Chang Gung Medical College, Tao Yuan, Taiwan, Republic of China

${ }^{2}$ Department of Family Medicine, Chang Gung Medical Center, Tao Yuan, Taiwan, Republic of China

${ }^{3}$ Graduate Institute of Occupational Medicine and Industrial Hygiene, National Taiwan University, Taipei, Taiwan, Republic of China

${ }^{4}$ Graduate Institute ofEnvironmentalHealth,ChinaMedicalCollege,Taiwan,Republic ofChina Contract grant sponsor: Chang Gung Medical Center; Contract grant number: NSC 85-2331-B-182-106; Contract grant sponsor: National Science Council in Taiwan; Contract grant number: NSC86-2621-B182-002-Z; NSC87-2621-B182-002-Z.

*Correspondence to: Jiin-Chyuan Luo, Department of Public Health, Chang Gung Medical College, 259 Wenhua 1st Road, Kweishan, Tao Yuan, 333 Taiwan, Republic of China.

E-mail: lu05485@mail.cgu.edu.tw

Accepted 7 October 2002

DOI 10.1002/ajim.10177. Published online in Wiley InterScience

(www.interscience.wiley.com)

\section{INTRODUCTION}

Epichlorohydrin (1-chloro-2,3,-epoxypropane) $(\mathrm{ECH})$ is a colorless liquid, used for the manufacture of epoxy resins, surface-active agents, adhesives, paints, varnishes, insecticides, and other agricultural chemicals. Absorption through inhalation and skin is of practical importance. ECH is a strong irritant of the eyes, respiratory tract, and skin. Eye and skin irritation/sensitization was observed in laboratory animals [Gardiner et al., 1993]. Repeated or prolonged exposure can also cause lung, liver, and kidney damage in experimental animals [Gardiner et al., 1993]. The USDHEW recommended standard [NIOSH, 1976 reported eye and 
nasal burning results from $20 \mathrm{ppm}$ ECH exposure; lung edema and renal lesions may result from exposures greater than $100 \mathrm{ppm}$; and liver damage may occur after exposure to very high concentration levels. Occasional cases of skin irritation or sensitization have been reported in the workplace [Ippen and Mathies, 1970; Beck and King, 1983; Prens et al., 1986]. But human epidemiological studies have not provided definitive evidence of an association between occupational $\mathrm{ECH}$ exposure and an increased incidence of organ injury or disease [Gardiner et al., 1993]. In this study, we examined the dose-response relationship between ECH and pulmonary function tests and respiratory tract irritation symptoms among ECH-exposed workers in Taiwan.

\section{MATERIALS AND METHODS}

In October 1996, a total of 167 workers were randomly selected from a total of 467 employees in three workstations of a resin synthesis factory in Taiwan where epoxy resin (workstation I), printed circuit (PC) boards (workstation II), and artificial leather (workstation III) are manufactured. Personal and area sampling were performed to determine $\mathrm{ECH}$, dimethylformamide (DMF), and toluene concentration exposure of workers. Details of the sampling methods and manufacturing processes are fully described in Kuo et al.
[2000]. Briefly, a total of 21 area sampling points were selected throughout the plant, based on proximity to sources of the solvent emissions; sampling time ranged from 30 to $180 \mathrm{~min}$. Forty-five workers were also selected at random for personal sampling.

Most workers engaged in epoxy resin manufacturing were considered to have increased $\mathrm{ECH}$ exposure; most workers in the PC board plant were considered to have both $\mathrm{ECH}$ and DMF exposure; and synthetic leather manufacturing plant workers were considered to have DMF exposure, and no ECH exposure. Study subjects were divided into three groups according to ECH exposure concentrations (Table I). The cut-off point for high and low exposure to ECH was defined arbitrarily to be $0.2 \mathrm{ppm}$ after considering equal sample size and work processes.

Informed consent was obtained from all subjects. Demographic data, work history, smoking status, and respiratory tract irritation symptoms were gathered by a standard self-administered questionnaire. In the symptoms questionnaire, we asked "Did you suffer from this symptom at least once a week in the past 3 months?" If the person answered "yes," we treated the response as positive for this symptom. Smokers were defined as those who smoked at least 3 days a week. Symptoms of chronic bronchitis were defined as having cough with phlegm at least 3 months each

TABLE I. Characteristics of Taiwan Workers by Categories of ECHExposure

\begin{tabular}{|c|c|c|c|c|}
\hline Variables & $\begin{array}{c}\text { High-ECH }^{\mathrm{a}} \\
(\mathrm{n}=41)\end{array}$ & $\begin{array}{l}\text { Low-ECH } \\
(\mathrm{n}=\mathbf{3 8})\end{array}$ & $\begin{array}{l}\text { Non-ECH } \\
(n=59)^{b}\end{array}$ & $\begin{array}{l}\text { No-ECH } \\
(n=88)^{\mathrm{C}}\end{array}$ \\
\hline \multicolumn{5}{|l|}{ Demographic } \\
\hline Age (years) ${ }^{d}$ & $29.9^{\star} \pm 5.3$ & $33^{\star} \pm 5.3$ & $37.3 \pm 5.7$ & $36.6 \pm 5.8$ \\
\hline Duration of employment (years) ${ }^{d}$ & $4.4^{*} \pm 2.0$ & $7.9^{\star} \pm 3.8$ & $10.8 \pm 6.0$ & $10.1 \pm 5.7$ \\
\hline Smoking & $19(46.3 \%)$ & $22(57.9 \%)$ & $33(55.9 \%)$ & $52(59.1 \%)$ \\
\hline \multicolumn{5}{|l|}{ Sex } \\
\hline No. (\%), male & $36(87.8 \%)$ & $38^{* \star}(100 \%)$ & $54(91.5 \%)$ & $82(93.2 \%)$ \\
\hline \multicolumn{5}{|l|}{ Pulmonary function } \\
\hline $\mathrm{FVC}(\% \text { pred })^{\mathrm{d}}$ & $102 \pm 16$ & $98 \pm 13.8$ & $99.1 \pm 12.8$ & \\
\hline $\mathrm{FEV}_{1} \% \mathrm{FVC}^{\mathrm{d}}$ & $87.1^{*} \pm 9.3$ & $88.6 \pm 7.4$ & $90.2 \pm 5.7$ & \\
\hline $\operatorname{MMEF}(\% \text { pred })^{d}$ & $72^{\star} \pm 19.7$ & $71.6^{\star} \pm 18.3$ & $82.5 \pm 18.1$ & \\
\hline $\mathrm{FEV}_{1}(\% \text { pred })^{d}$ & $93.9^{\star} \pm 11.4$ & $94.3^{*} \pm 12.2$ & $99.7 \pm 11$ & \\
\hline \multicolumn{5}{|l|}{ Exposure } \\
\hline $\mathrm{ECH}(\mathrm{ppm})^{\mathrm{d}}$ & $1.7^{\star} \pm 2$ & $0.064^{*} \pm 0.05$ & $0 \pm 0$ & $0 \pm 0$ \\
\hline $\operatorname{DMF}(\mathrm{ppm})^{d}$ & $3^{*} \pm 0.8$ & $13.9 \pm 10$ & $11.5 \pm 12.4$ & $14.8 \pm 16.8$ \\
\hline Toluene $(\mathrm{ppm})^{\mathrm{d}}$ & $1.6^{\star} \pm 0.74$ & $1.05 \pm 0.49$ & $7.33 \pm 13.5$ & $8.98 \pm 14.3$ \\
\hline
\end{tabular}

${ }^{a} E C H$, epichlorohydrine (high $\geq 0.2$ ppm; low $<0.2,>0$ ppm; no = 0 ppm); FVC (\% pred), forced vital capacity; $F_{E V} \% F V C$, forced expiratory volume in $1 \mathrm{sec}$ as a percentage of $\mathrm{FVC}$; $\mathrm{MMEF}$, mean mid-expiratory flow; $\mathrm{FEV}_{1}$, 1-second forced expiratory volume. ${ }^{\mathrm{b}}$ Non-ECH-exposed workers with PFT available.

${ }^{\mathrm{c} A l l}$ non-ECH-exposed workers.

${ }^{\mathrm{d}}$ Mean \pm SD.

${ }^{\star} P<0.05$, difference compared to non-ECH-exposed group.

${ }^{\star \star} P<0.1$, difference compared to non-ECH-exposed group. 
year for at least two consecutive years [Fletcher and Pride, 1984; ATS, 1987; Snider, 1989].

All high-ECH-exposed and low-ECH-exposed workers, and 59 workers who were randomly sampled from 88 nonECH-exposed workers performed pulmonary function tests. During each pulmonary function test, we obtained raw lung function values and the percentage of predicted values, which were compared with the nomogram for Asian people of the same sex, age, and height.

The data from the 167 workers were encoded, entered, and analyzed with the assistance of the Statistical Analysis System (SAS) PC software Package [SAS Institute, 1990] and Database III plus, 1986. We used Student $t$-test and ANOVA to test the differences among the working sections and controls in means of predicted forced vital capacity (FVC) value, forced expiratory volume in $1 \mathrm{sec}$ as a percentage of FVC ( $\left.\mathrm{FEV}_{1} \% \mathrm{FVC}\right)$, and mean mid-expiratory flow (MMEF). Abnormalities of the pulmonary function tests were defined as the predicted $\mathrm{FVC}<80 \%, \mathrm{FEV}_{1} \% \mathrm{FVC}<$ $75 \%$, and the predicted $\mathrm{MMEF}<60 \%$, respectively. Two by two tables and chi-square $\left(\chi^{2}\right)$ tests were performed to test differences in the proportions of abnormal pulmonary function tests and symptoms. Odds ratios with $95 \%$ confidence intervals (CI) were calculated to show the magnitude and the difference in prevalence of pulmonary function abnormality and symptoms between exposure groups and the non-ECH exposed group. Mantel-Haenszel chi-square test was applied to calculate the smoking, sex, duration of employment, and DMF exposure-adjusted odds ratio. Pearson correlation analysis was used to detect the relationship between any two variables. Multivariate regression analysis was used to control for the effects of potential confounders on the association between exposure groups and lung function tests. Chi-square test was also performed to test the linear trend between exposure concentration and positivity.

\section{RESULTS}

The basic characteristics of the study cohort are summarized in Table I. Job descriptions of the 38 low$\mathrm{ECH}$-exposed workers with an average of $0.064 \mathrm{ppm} \mathrm{ECH}$ exposure included dipping of glass fiber sheets with epoxy resin, materials mixing, chemicals recycling, and safety officers in PC board production. Job descriptions of the 88 non-ECH-exposed workers included spraying of textile with polyurethane resin, mixing, maintenance, printing, research and development, quality control, textile preparation in synthetic leather production, PC board pressing and assembling, and office workers. Non-ECH-exposed workers were significantly older than high- and low-exposed workers, had a significantly longer duration of employment and a higher prevalence of female workers than the other two groups. There were significantly lower values for average lung function tests $\left(\mathrm{FEV}_{1} \% \mathrm{FVC}, \mathrm{MMEF}, \mathrm{FEV}_{1}\right)$ in high-ECHexposed workers than in the non-ECH-exposed group (FEV ${ }_{1} \%$ FVC 87.1 vs. 90.2; MMEF 72 vs. 82.5; FEV $_{1} 93.9$ vs. 99.7). There were significantly lower values for average lung function tests $\left(\mathrm{MMEF}, \mathrm{FEV}_{1}\right)$ in low-ECH-exposed workers than in the non-ECH-exposed group (MMEF 71.6 vs. 82.5; $\mathrm{FEV}_{1} 94.3$ vs. 99.7). There was no statistical difference between 59 workers with tests and 88 non-ECHexposed workers in demographic data (age, duration of employment, smoking status, and sex distribution) and DMF, and toluene exposure concentrations.

Table II shows prevalence of abnormal lung function tests by categories of ECH exposure. There were 13 (31.7\%) abnormal MMEF values among high-ECH-exposed workers, $11(29 \%)$ among the low-ECH-exposed workers, and four $(6.8 \%)$ among non-ECH-exposed workers. There was a significant linear trend between ECH exposure and the prevalence of abnormal MMEF values $(P=0.007)$ after adjusting for other factors. There were 4 (9.8\%) abnormal

TABLE II. Prevalence of Abnormal Pulmonary FunctionTests by Categories of ECHExposure Among ECH-Exposed Workers inTaiwan

\begin{tabular}{|c|c|c|c|c|}
\hline Variables & High-ECH $(n=41)$ & Low-ECH $(\mathrm{n}=38)$ & Non-ECH $(n=59)$ & Total $(n=138)$ \\
\hline $\mathrm{MMEF}^{\mathrm{a}}$ & $13(31.7 \%)$ & $11(29 \%)$ & $4(6.8 \%)$ & $28(20.3 \%)$ \\
\hline $\mathrm{OR}(95 \% \mathrm{Cl})^{\mathrm{b}}$ & $7.46(1.63,34.1)$ & $6.82(1.75,26.6)$ & 1 & $0.007^{\mathrm{c}}$ \\
\hline $\mathrm{FEV}_{1} \% \mathrm{FVC}$ & $4(9.8 \%)$ & $2(5.3 \%)$ & $1(1.7 \%)$ & $7(5.1 \%)$ \\
\hline OR $(95 \% \mathrm{Cl})$ & $15.3^{\star \star}(0.66,354)$ & $3.82(0.28,52.5)$ & 1 & 0.16 \\
\hline FVC & $3(7.3 \%)$ & $4(10.5 \%)$ & $3(5.1 \%)$ & $10(7.2 \%)$ \\
\hline OR $(95 \% \mathrm{Cl})$ & $0.98(0.13,7.24)$ & $2.54(0.47,13.8)$ & 1 & 0.69 \\
\hline
\end{tabular}

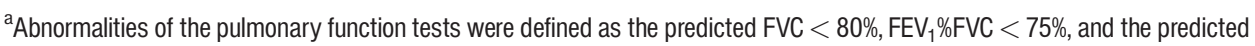
MMEF $<60 \%$, respectively.

${ }^{\mathrm{b}} \mathrm{OR}$, adjusted Odds Ratio for smoking, sex, duration of employment, DMF.

${ }^{\mathrm{c}} P$ value in liner trend test.

${ }^{\star \star} P<0.1$, difference compared to non-ECH-exposed group.
} 
$\mathrm{FEV}_{1} \% \mathrm{FVC}$ values among high-ECH-exposed workers, 2 (5.3\%) among low-ECH-exposed, and 1 (1.7\%) among nonECH-exposure workers.

In multivariate logistic regression analysis, high $\mathrm{ECH}$ exposure and low ECH exposure were significantly associated with abnormal MMEF values $(P=0.0085$ and $P=0.005$, respectively) after adjusting for other factors (Table III). High ECH exposure was also borderline significantly associated with abnormal $\mathrm{FEV}_{1} \% \mathrm{FVC}$ values $(P=0.083)$. Neither sex, duration of employment, smoking status, nor DMF exposure was significantly associated with lung function abnormalities. Age was significantly correlated with duration of employment $(\mathrm{r}=0.684, P=0.0001)$ (data not shown).

The results of respiratory tract symptoms were shown in Tables IV and V. Twelve (29.3\%) high-ECH-exposed workers, 11(29\%) low-ECH-exposed workers, and 13 (14.8\%) non-ECH-exposed workers reported cough symptoms. There was a significant linear trend between ECH exposure and the prevalence of cough symptoms $(P=0.019)$ after adjusting for sex, duration of employment, and DMF exposure. Ten (24.4\%) high-ECH-exposed workers, 11(29\%) lowECH-exposed, and 17 (19.3\%) non-ECH-exposed workers reported phlegm symptoms. There was a significant linear trend between ECH exposure and the prevalence of phlegm symptoms $(P=0.047)$ after adjusting for other factors.

TABLE III. Multivariate Logistic Regression Analyses Between Abnormal Pulmonary Function Tests and Related Indicators for ECH-Exposed Workers inTaiwan

\begin{tabular}{|c|c|c|c|}
\hline & MMEF $^{\mathrm{a}}$ & FEV $_{1} \%$ FVC & FVC \\
\hline \multicolumn{4}{|l|}{ Duration } \\
\hline $0(>8)$ & $1.12(0.35,3.56)^{b}$ & $2.16(0.23,19.9)$ & $1.19(0.24,5.87)$ \\
\hline \multicolumn{4}{|l|}{$1(\leq 8)$} \\
\hline \multicolumn{4}{|l|}{ Smoking } \\
\hline 1 (yes) & $0.91(0.35,2.39)$ & $1.84(0.3,11.4)$ & $0.64(0.16,2.56)$ \\
\hline \multicolumn{4}{|l|}{0 (no) } \\
\hline \multicolumn{4}{|l|}{ Sex } \\
\hline $1(\mathrm{~m})$ & $0.25(0.05,1.35)$ & $0.29(0.02,4.4)$ & 26.5 \\
\hline \multicolumn{4}{|l|}{$0(\mathrm{f})$} \\
\hline \multicolumn{4}{|c|}{ Exposure categories } \\
\hline 1 (high ECH) & $7.46(1.63,34.1)^{\star}$ & $15.3(0.66,354)$ & $0.98(0.13,7.24)$ \\
\hline \multicolumn{4}{|l|}{0 (no ECH) } \\
\hline 1 (low ECH) & $6.82(1.75,26.6)^{\star}$ & $3.82(0.28,52.5)$ & $2.54(0.47,13.8)$ \\
\hline \multicolumn{4}{|l|}{0 (no ECH) } \\
\hline \multicolumn{4}{|l|}{ DMF } \\
\hline 1 (>10 ppm) & $1.26(0.37,4.3)$ & $2.39(0.19,30.3)$ & $0.14(0.01,1.28)$ \\
\hline $0(\leq 10 \mathrm{ppm})$ & & & \\
\hline
\end{tabular}

${ }^{a}$ Abnormalities of the pulmonary function tests were defined as the predicted $\mathrm{FVC}<80 \%, \mathrm{FEV}_{1} \% \mathrm{FVC}<75 \%$, and the predicted MMEF $<60 \%$. (yes $=1$, no $=0$ ). ${ }^{\mathrm{b}}$ Odds Ratio adjusting for other indicators.

${ }^{*} P<0.05$.
Sixteen (39\%) high-ECH-exposed workers, 12 (31.6\%) lowECH-exposed workers, and 16 (18.2\%) non-ECH-exposed workers had chest tightness symptoms. There was a significant linear trend between ECH exposure and the prevalence of chest tightness symptoms $(P=0.038)$ after adjusting for other factors. Seven (17.1\%) high-ECH-exposed workers, five $(13.2 \%)$ low-ECH-exposed workers, and three (3.4\%) non-ECH-exposed workers reported dyspnea symptoms. There was a borderline significant linear trend between ECH exposure and the prevalence of dyspnea symptoms $(P=0.078)$ after adjusting for other factors.

In multivariate logistic regression analysis, high $\mathrm{ECH}$ exposure and low ECH exposure were significantly associated with cough, phlegm, chest tightness, and dyspnea symptoms after adjusting for other factors (Table V). Chronic bronchitis was significantly associated with smoking status ( $P=0.043)$ after being adjusted for other factors, but it was not associated with ECH exposure. Females had significantly more complaints of chest tightness $(P=0.02)$ and dyspnea $(P=0.066)$. Cough and phlegm symptoms were also significantly associated with duration of employment $(P=0.074$, and $P=0.013$, respectively).

\section{DISCUSSION}

Obstructive lung function abnormalities and small airway lung dysfunction were associated with ECH exposure. There was a significantly higher prevalence of small airway abnormalities in ECH workers than in control workers, and a significant dose response between prevalence of small airway abnormalities and ECH air concentration was observed. There was a borderline significantly higher prevalence of obstructive lung abnormalities in high-ECH workers than in control workers, but not when compared to the low-ECH group. Our study suggests that exposure to low $\mathrm{ECH}(<0.2 \mathrm{ppm})$ is enough to cause small airway abnormalities, but high ECH (range 0.2-5.9 ppm) is needed to cause obstructive lung abnormalities.

Small airways under $2 \mathrm{~mm}$ in diameter are the primary site of deposition of inhaled toxins and can be affected earliest and most severely [Rao et al., 1992; Chiang and Hsu, 1997]. MMEF is a simple, sensitive, and early indicator of obstruction in smaller airways [Rao et al., 1992; Chiang and Hsu, 1997]. Methacholine inhalation provocation tests are noted to be helpful in evaluating an asymptomatic individual worker with suspected occupational asthma, or identifying workers with already hyper-reactive airways who might be at greater risk for disease [Pepys and Hutchcroft, 1975; ATS, 1980; Anonymous, 1989; Brooks et al., 1990]. Twenty-eight of 79 (35.4\%) ECH-exposed workers had obstructive or small airway lung lesions, seven of them received provocation tests, and one (14.3\%) worker proved to have a hypersensitive airway. He is a 33 -year-old male maintenance worker with 5 years on the job and $1.1 \mathrm{ppm}$ ECH exposure. 
TABLE IV. Prevalence of Respiratory Tract Irritation Symptoms by Categories of ECH Exposure Among ECH-Exposed Workers inTaiwan

\begin{tabular}{cccc} 
Variables & High-ECH $(\mathbf{n}=\mathbf{4 1})$ & Low-ECH $(\mathbf{n}=\mathbf{3 8})$ & Total $(\mathbf{n}=\mathbf{1 6 7})$ \\
\hline Running nose & 10 & 5 & 30 \\
OR $(95 \% \mathrm{Cl})^{\mathrm{a}}$ & $1.54(0.45,5.27)$ & $0.74(0.23,2.32)$ & $0.68^{\mathrm{b}}$ \\
Stuffy nose & 13 & 9 & 44 \\
OR $(95 \% \mathrm{Cl})$ & $1.37(0.43,4.44)$ & $1.29(0.5,3.35)$ & 0.42 \\
Sneezing & 15 & 7 & 44 \\
OR $(95 \% \mathrm{Cl})$ & $2.92(0.77,11.1)$ & $0.87(0.37,2.08)$ & 0.16 \\
Sore throat & 12 & 8 & 34 \\
OR $(95 \% \mathrm{Cl})$ & $2.49(0.59,10.5)$ & $1.46(0.54,3.95)$ & 0.22 \\
Cough & 12 & 11 & 36 \\
OR $(95 \% \mathrm{Cl})$ & $4.71(1.36,16.3)$ & $2.92(1.07,7.92)$ & 0.019 \\
Phlegm & 10 & 11 & 38 \\
OR $(95 \% \mathrm{Cl})$ & $3.74(1.08,12.9)$ & $2.36^{\star \star}(0.89,6.3)$ & 0.047 \\
Chronic bronchitis & 3 & 6 & 17 \\
OR $(95 \% \mathrm{Cl})$ & $1.6(0.28,9.3)$ & $2.46(0.71,8.5)$ & 0.58 \\
Wheezing & 4 & 4 & 12 \\
OR $(95 \% \mathrm{Cl})$ & 16 & $2.71(0.65,11.3)$ & 0.26 \\
Chest tightness & $3(1.04,8.67)$ & 12 & 44 \\
OR $(95 \% \mathrm{Cl})$ & 7 & $2.41^{\star \star}(0.94,6.2)$ & 0.038 \\
Dyspnea & $4.86(0.85,27.7)$ & 5 & 15 \\
OR $(95 \% \mathrm{Cl})$ & $5.1(1.01,25.8)$ & 0.078 \\
\hline
\end{tabular}

${ }^{\mathrm{a} O R}$, Odds Ratio adjusting for smoking, sex, duration of employment, DMF.

${ }^{\mathrm{b}} P$ value in liner trend test.

${ }^{\star \star} P<0.1$, difference compared to non-ECH-exposed group.

TABLE V. Multivariate Logistic Regression Analyses Between Respiratory Tract Symptoms and Related Indicators for ECH-Exposed Workers in Taiwan

\begin{tabular}{|c|c|c|c|c|c|}
\hline Variables & Cough & Phlegm & Chronic bronchitis & Chest tightness & Dyspnea \\
\hline \multicolumn{6}{|l|}{ Duration } \\
\hline $1(>8)$ & $2.34(0.9,6.11)^{\mathrm{a}}$ & $3.19(1.25,8.17)^{b}$ & $2.29(0.68,7.77)$ & $0.86(0.36,2.08)$ & $0.7(0.15,3.19)$ \\
\hline \multicolumn{6}{|l|}{$0(\geq 8)$} \\
\hline \multicolumn{6}{|l|}{ Smoking } \\
\hline 1 (yes) & $1(0.45,2.23)$ & $1.54(0.68,3.49)$ & $3.9(1.02,14.9)$ & $1.55(0.7,3.46)$ & $1.04(0.3,3.68)$ \\
\hline \multicolumn{6}{|l|}{$0(\mathrm{no})$} \\
\hline \multicolumn{6}{|l|}{ Sex } \\
\hline $1(\mathrm{~m})$ & $2.75(0.29,25.8)$ & $1.93(0.21,18.2)$ & 25 & $0.18(0.04,0.8)$ & $0.18(0.029,1.16)$ \\
\hline \multicolumn{6}{|l|}{$0(\mathrm{f})$} \\
\hline \multicolumn{6}{|c|}{ Exposure categories } \\
\hline 1 (high ECH) & $4.71(1.36,16.3)$ & $3.74(1.08,12.9)$ & $1.6(0.28,9.3)$ & $3(1.04,8.67)$ & $4.86(0.85,27.7)$ \\
\hline \multicolumn{6}{|l|}{0 (no ECH) } \\
\hline 1 (low ECH) & $2.92(1.07,7.92)$ & $2.36(0.89,6.3)$ & $2.46(0.71,8.5)$ & $2.41(0.94,6.17)$ & $5.1(1.01,25.8)$ \\
\hline \multicolumn{6}{|l|}{0 (no ECH) } \\
\hline \multicolumn{6}{|l|}{ DMF } \\
\hline 1 (>10 ppm) & $1.17(0.46,3)$ & $1.45(0.59,3.56)$ & $0.94(0.29,3.07)$ & $1.19(0.48,2.92)$ & $1.06(0.23,4.95)$ \\
\hline $0(\leq 10 \mathrm{ppm})$ & & & & & \\
\hline
\end{tabular}

${ }^{a}$ Odds Ratio adjusting for other indicators.

${ }^{\mathrm{b}} \mathrm{P}<0.05$. 
He complained of cough with phlegm, chest tightness, wheezing, and dyspnea for at least the past 3 months. His obstructive lung abnormalities returned to normal 5 months later $\left(\mathrm{FEV}_{1} / \mathrm{FVC} 53.4 \% \rightarrow 86.5 \%\right.$; MMEF $\left.50.7 \% \rightarrow 64 \%\right)$ after medical treatment, and by avoiding unnecessary exposure through adequate personal respiratory protection and proper engineering controls in the plant. During the 5 months of follow-up, the lung function of five out of six negative provocation workers also had recovered for the same reasons. The above results indicate that ECH might cause reversible obstructive lung abnormalities via airway irritation and inflammation, and also might cause a hyperactive airway.

There was a significantly higher prevalence of respiratory tract irritation symptoms (cough, phlegm, chest tightness, and dyspnea) in ECH-exposed workers than in non-ECH-exposed workers, and there was a significant dose response between the prevalence of the above symptoms and $\mathrm{ECH}$ air concentrations. These are consistent with results of other reports [Hine and Rowe, 1968; Wexler, 1971; NIOSH, 1976; Gardiner et al., 1993] that airway irritation can occur in ECH-exposed workers. Results also indicate that exposure to very low concentrations $(<0.2 \mathrm{ppm})$ which was far below the current OSHA TLV of $2 \mathrm{ppm}$ can cause a significantly higher prevalence of symptoms over non-exposure.

Respiratory tract irritants represent a diverse spectrum of compounds, gases, and chemicals that when inhaled result in irritation to mucous membranes manifested as nonspecific inflammation. The water solubility and concentration of the irritants determine the site of injury. Extremely water-soluble compounds such as ammonia cause injury in the upper airway, whereas insoluble gases such as the nitrogen oxides cause peripheral airway and alveolar injury. ECH is a less soluble gas with a $6.48 \%$ water solubility, which might explain its effect on the lower respiratory tract and not on the upper airway.

The precise mechanism of ECH-induced airway abnormalities is still unclear. Studies on the other less watersoluble gases such as nitrogen oxides and ozone may shed light on the above. Studies in animal model show that nitrogen dioxide exposure may produce morphologic alterations in the terminal and respiratory bronchioles and adjacent alveolar ducts and alveoli [Evans et al., 1972, 1975; Rombout et al., 1986; Kubota et al., 1987]. Within the ciliated cells of bronchiolar epithelium, acute exposure results in hypertrophy and hyperplasia of the type 1 cells followed by death and desquamation of these cells and proliferation and replacement by type 2 and causes a thickened air-blood barrier. Chronic exposure may result in alterations in lung architecture resembling those of emphysema [Haydon et al., 1965; Glasgow et al., 1987]. Studies on ozone described inflammatory and biochemical changes in the airways following ozone exposure [Sletzer et al., 1986; Koren et al., 1989; Chang et al., 1998]. Ozone-induced airway reactivity to methacholine was associated with polymorphonuclear leukocyte (PMN) influx into airways with interleukin 8 and changes in cyclooxygenase metabolites of archidonic acid.

DMF and toluene are not noted to cause pulmonary function abnormality and respiratory tract irritation. Glass fiber can induce upper respiratory tract irritant responses. There have been few case reports of pulmonary disease due to glass fiber exposure. Prevalence studies of chest radiographic findings, respiratory symptoms, and lung function in exposed workers have in general been negative [Christiani and Wegman, 2000]. Fibrous glass sheet was used in the PC board production in this study. Twenty of the 38 low$\mathrm{ECH}$-exposed workers have been exposed to glass fiber dust during the dipping process of PC board production. Using 18 no-fiber-exposed workers in low-ECH-exposed group as control, the association between fiber exposure and respiratory symptoms and lung function are as follow: running nose $(\mathrm{r}=0.057, P=0.73)$, stuffy nose $(\mathrm{r}=-0.032, P=0.85)$, sneezing $(-0.093, P=0.58)$, cough $(\mathrm{r}=0.025, P=0.88)$, phlegm $(\mathrm{r}=-0.092, P=0.58)$, chest tightness $(\mathrm{r}=-0.15$, $P=0.37)$, dyspnea $(\mathrm{r}=-0.099, P=0.56)$, wheezing $(\mathrm{r}=$ $-0.19, P=0.25)$, chronic bronchitis $(\mathrm{r}=-0.023, P=0.9)$, $\mathrm{FVC}(\mathrm{r}=0.09, P=0.6), \mathrm{FEV}_{1} \% \mathrm{FVC}(\mathrm{r}=0.084, P=0.62)$ and MMFP $(r=0.09, P=0.59)$. Our data was consistent with Christani's article in that there was no association between glass fiber exposure and respiratory symptoms, lung function tests.

This study showed no association between chronic bronchitis and ECH exposure. It may indicate the current ECH exposure concentration of 1.1(02-5.9 ppm), and duration of employment of 4.4 (1-9 years) in high-exposed group was not enough to cause chronic lung abnormalities. Further follow-up of this cohort will clarify this observation.

This study found a significant association between tobacco smoking and symptoms of chronic bronchitis, which confirms that smoking is the major cause of chronic bronchitis [Koren et al., 1989; Chang et al., 1998; Sethi and Rochester, 2000]. Smoking also can cause obstructive lung function abnormalities [Freedman et al., 1972; Fletcher et al., 1976; Burrows et al., 1977; PHS, 1984; Dockery et al., 1988; Chang et al., 1998; Senior and Shapiro, 1998]. In this study, there was no significant relationship between small airway abnormalities or obstructive lung abnormalities and smoking status. The crude estimation of smoking status may have contributed to this finding. Further precise delineation of smoking patterns may be able to clarify this effect.

This study is limited by its small sample size and thus results in borderline significance inherent in a cross-sectional design. This study suggests that obstructive lung abnormalities might be produced by ECH concentrations (range $0.2-5.9 \mathrm{ppm})$ and that exposure to very low concentrations $(<0.2 \mathrm{ppm})$ which are far below the current OSHA TLV of $2 \mathrm{ppm}$ might cause a significantly higher prevalence of small airway lung dysfunction and airway irritation symptoms. Causal inferences from the findings cannot be made 
from this cross-sectional study and further longitudinal studies are needed to better clarify the nature of the observed associations.

\section{ACKNOWLEDGMENT}

We thank Dr. Paul Brandt-Rauf for his thoughtful comments.

\section{REFERENCES}

American Thoracic Society (ATS). 1980. Guidelines for bronchial inhalation challenges with pharmacological and antigenic agents. ATS News. Spring.

American Thoracic Society (ATS). 1987. Standards for the diagnosis and care of patients with chronic obstructive pulmonary disease (COPD) and asthma. Am Rev Respir Dis 136:225-244.

Anonymous. 1989. Guidelines for the diagnosis and evaluation of occupational immunologic lung disease. J Allergy Clin Immunol 84: $791-838$.

Beck MH, King CM. 1983. Allergic contact dermatitis to epichlorohydrin in a solvent cement. Contact Derm 9:315.

Brooks S, Baker DB, Gann PH. 1990. Cold air challenge and platinum skin reactivity in platinum refinery workers. Chest 97:1401-1407.

Burrows B, Knudson RJ, Cline MG. 1977. Quantitative relationships between cigarette smoking and ventilatory function. Am Rev Respir Dis 115:195-205.

Chang MM, Wu R, Plopper CG, Hyde DM. 1998. IL-8 is one of the major chemokines produced by monkey airway epithelium after ozoneinduced injury. Am J Physiol 275:L524-L532.

Chiang CH, Hsu K. 1997. Residual abnormalities of pulmonary function in asymptomatic young adult asthmatics with childhood-onset asthma. J Asthma 34:15-21.

Christiani DC, Wegman DH. 2000. Respiratory disorders. In: Levy BS, Wegman DH, editors. Occupational health-Recognizing and preventing work-related disease and injury. 4th edition. Philadelphia: Lippincott Williams \& Wilkins. p 477-501.

Database III plus. 1986. Torrance, CA: Ashton-Tate.

Dockery DW, Speizer FE, Ferris BG,Jr., Ware JH, Louis TA, Spiro A 3rd. 1988. Cumulative and reversible effects of lifetime smoking on simple tests of lung function in adults. Am Rev Respir Dis 137:286-292.

Evans MJ, Stephens RJ, Carbral LJ, Freeman G. 1972. Cell renewal in the lungs of rats exposed to low levels of $\mathrm{NO}_{2}$. Arch Environ Health $24: 180-188$

Evans MJ, Carbral LJ, Stephen RJ, Freeman G. 1975. Transformation of alveolar type 2 cells to type 1 cells following exposure to NO2. Exp Mol Pathol 22:142-150.

Fletcher CM, Pride NB. 1984. Definitions of emphysema, chronic bronchitis, asthma and airflow obstruction: 25 Years on from the Ciba Symposium. Thorax 39:81-85.

Fletcher C, Peto R, Tinker C. 1976. The natural history of chronic bronchitis and emphysema. London: Oxford University Press.

Freedman S, Fletcher CM, Field GB. 1972. Effects of smoking modified cigarettes on respiratory symptoms and ventilatory capacity. J Natl Cancer Inst 48:1805-1810.

Gardiner TH, Waechter JM, Stevenson DE. 1993. Epichlorohydrin. In: Clayton GD, Clayton FE, editors. Patty's industrial hygiene and toxicology. 4th Edition. Vol. II, Part A. New York: Wiley-Interscience. p 417-422.

Glasgow JE, Pietra GG, Abrams WR, Blank J, Oppenheim DM, Weibaum G. 1987. Neutrophil recruitment and degranulation during induction of emphysema in the rats by nitrogen dioxide. Am Rev Respir Dis 135:1129-1136.

Haydon GB, Freeman G, Furiosi NJ. 1965. Covert pathogenesis of NO2induced emphysema in the rat. Arch Environ Health 11:776-783.

Hine CH, Rowe VK. 1968. Epichlorohydrin. In: Patty FA, editor. Industrial hygiene and toxicology. 2nd Edition. Vol 2. New York: Interscience. p 1622-1625.

Ippen H, Mathies B. 1970. Protracted chemical burns with special regard to skin damage caused by epoxide and propane sultane. Berufsdermatosen 18:144-165.

Koren HS, Devlin RB, Graham D. 1989. Ozone-induced inflammation in the lower airways of humans subjects. Am Rev Respir Dis 139:407-415.

Kubota K, Murakami S, Takenaka K, Kawai H. 1987. Effects of longterm nitrogen dioxide exposure on rat lung: Morphological observations. Environ Health Perspect 73:157-169.

Kuo HW, Huang YS, Lo JC, Cheng TJ, Wu MJC. 2000. Exposure to solvents in a synthetic leather manufacturing plant. Int Arch Occup Health 73:275-280.

National Institute for Occupational Safety and Health, US Department of Health, Education and Welfare. Criteria for a Recommended Standard, Occupational Exposure to Epichlorohhydrin.1976. DHEW (NIOSH) Pub No. 76-206. Washington, DC: US Government Printing Office. p 1-152.

Pepys J, Hutchcroft BJ. 1975. Bronchial provocation tests in etiologic diagnosis and analysis of asthma. Am Rev Respir Dis 112:829-859.

Prens EP, Jong GD, Joost TV. 1986. Sensitization to epichlorohydrin and epoxy system components. Contact Derm 15:315.

Public Health Service (PHS). 1984. The Health Consequences of Smoking: Chronic Obstructive Lung Disease. 1984. A report of the Surgeon General. Washington D.C.: US Department of Health and Human Services, Public Health Service, Office on Smoking and Health, DHHS Publication No. (PHS) 84-50205.

Rao NM, Patel TS, Raiyani CV. 1992. Pulmonary function status of shopkeepers of Ahmedabad exposed to autoexhaust pollutants. Indian J Physiol Pharmacol 36:60-64.

Rombout PJA, Dormans JAMA, Marra M, van Esch FJ. 1986. Influence of exposure regimen on nitrogen dioxide-induced morphological changes in the rat lung. Environ Res 41:466-480.

SAS Institute. 1990. SAS Statistical Package, Version 6. Cary, NC: SAS Institute, Inc.

Senior RM, Shapiro SD. 1998. Chronic obstructive pulmonary disease: Epidemiology, pathophysiology, and pathogenesis. In: Fishman AP, Elias JA, Fishman JA, editors. Fishman's pulmonary diseases and disorders. 3rd editon. New York: The McGraw-Hill Companies Inc. p 680.

Sethi JM, Rochester CL. 2000. Smoking and obstructive pulmonary disease. Clin Chest Med 21:67-86.

Sletzer J, Bigby BG, Stulbarg M, Holtzman MJ, Nadel JA. 1986. O ${ }_{3-}$ induced change in bronchial reactivity to methacholine and airway inflammation in humans. J Appl Physiol 60:1321-1326.

Snider GL. 1989. Chronic obstructive pulmonary disease: A definition and implications of structural determinations of airflow obstruction for epidemiology. Am Rev Respir Dis 140:S3-S8.

Wexler B. 1971. Determination of epichlorohydrin contamination in an industrial facility for the manufacturing of epoxy resins. Mater Plast (Bucharest) 8:322-323. 